\title{
Parity of esteem begins at home: translating empirical psychiatric research into effective public mental health
}

\author{
J. B. Kirkbride* and P. B. Jones \\ Department of Psychiatry, University of Cambridge, Cambridge, UK
}

\begin{abstract}
There is increasing recognition that parity of esteem between mental and physical health disorders is essential to improve the course, outcome and quality of life of individuals within different populations. Achieving this parity now underpins the objectives of several nations. Here, we argue that parity of esteem between mental and physical health can only be realized when parity of esteem also exists across mental health disorders, particularly in terms of service commissioning and planning. Using first-episode psychosis and early intervention in psychosis services as a motivating example, we demonstrate how carefully conducted psychiatric epidemiology can be translated to develop precise forecasts of the anticipated incidence of first-episode psychosis in different populations, based on an understanding of underlying local needs and inequalities. Open-access prediction tools such as PsyMaptic will allow commissioners of mental health services to more effectively allocate resources across services, based on empirical evidence and local need, thus reducing inequalities in access to mental health care.
\end{abstract}

Received 2 May 2013; Revised 10 July 2013; Accepted 10 July 2013; First published online 9 August 2013

Key words: Early intervention in psychosis, health services research, parity of esteem, prediction, public mental health.

\section{Introduction}

Achieving parity of esteem between mental and physical health has become a major priority in several countries within the last 12 months. At a recent White House conference on mental health, the 44th President of the USA, Barack Obama, issued a statement to say that from 2014, no healthcare provider in the USA would be allowed to deny anyone insurance on the basis of pre-existing mental health problems (The White House, 2013), effectively putting in motion the country's 2008 Paul Wellstone and Pete Domenici Parity and Addiction Equity Act. There is growing pressure in other countries, too, to make parity of esteem between mental and physical health a key goal. On the last World Health Day the President of the Royal College of Psychiatrists, Professor Sue Bailey, was joined by colleagues from Australia, New Zealand and Canada in calling upon governments across the world to give equal footing to mental and physical health (Royal College of Psychiatrists, 2012), with publication of the College's landmark report, 'Whole-Person Care: from rhetoric to reality' setting

* Address for correspondence: J. B. Kirkbride, Department of Psychiatry, Herchel Smith Building for Brain and Mind Sciences, Forvie Site, Robinson Way, Cambridge CB2 0SZ, UK.

(Email: jbk25@cam.ac.uk) forth a blueprint for realizing this aim (Royal College of Psychiatrists, 2013).

\section{Physical and mental co-morbidity in people experiencing psychosis}

It is now widely recognized that a high degree of co-morbidity exists between mental and physical health (Lasser et al. 2000; Grant et al. 2004; Egede, 2007; Moussavi et al. 2007; McManus et al. 2010; Department of Health, 2011; Campion et al. 2012). As such, improved outcomes in one domain will probably require investment in the other. One of the starkest challenges facing the parity of esteem agenda is the reduced life expectancy of between 10 and 25 years in people diagnosed with schizophrenia (Laursen et al. 2012). This is not due solely to elevated rates of suicide in this population, with excess mortality primarily attributable to cardiovascular and respiratory diseases (Mortensen \& Juel, 1993; Brown et al. 2000; Saha, 2007; Lawrence et al. 2010; Department of Health, 2011). While side-effects of anti-psychotic medication are probably an important contributor to this, people with pre-existing mental health disorders also tend to receive poorer physical health care (Kohn et al. 2004; Mitchell et al. 2009; Lord et al. 2010), tend to lead more unhealthy life-styles (Brown et al. 1999; McCreadie, 2003) and are less likely to receive behavioural and life-style advice, including in 
regard to smoking cessation (Campion et al. 2012). The prevalence of tobacco smoking in people with psychotic disorder (Lasser et al. 2000), including those in early intervention in psychosis settings (Wade et al. 2006; James \& Das, 2012), is estimated to be as high as $70 \%$.

Although the incidence and prevalence of psychotic disorders is lower than for other psychiatric conditions, they nevertheless contribute substantially to lifelong social, functional and physical disability (Rossler et al. 2005), given their often poor prognoses and early age at onset. As such, the cost to health services and society of psychotic disorders is relatively large; in 2005/6 the total cost of schizophrenia alone was estimated to be $£ 6.7$ billion in England (Mangalore \& Knapp, 2007), and similar costs for all psychotic disorders in Europe have more recently been estimated to be the third highest of any psychiatric disorder, narrowly behind common mental disorders and dementias (Gustavsson et al. 2011).

\section{Development and controversies of early intervention in psychosis services (EIS)}

Beginning in the last decade of the previous millennium, empirical evidence began to suggest that earlier clinical intervention following the onset of psychotic symptoms led to better health and social outcomes for people with severe mental illness (McGorry et al. 1996), with fewer relapses and readmissions later in life. A longer duration of untreated psychosis (DUP) is known to be predictive of poorer clinical and social outcomes (Marshall et al. 2005; Perkins et al. 2005). The idea of early intervention in psychosis gained sufficient momentum for multidisciplinary EIS to be introduced nationally in many countries, including England (Department of Health, 2001), Australia and New Zealand. Further, specialist first-episode psychosis (FEP) services, including prodromal and early intervention initiatives, have also been established on an ad hoc basis elsewhere, including the USA (Addington et al. 2012; Caplan et al. 2013), Canada (Iyer et al. 2010), India (Iyer et al. 2010), Brazil (Brietzke et al. 2011), South Korea (Lee et al. 2012), Hong Kong (Hui et al. 2013) and Japan (Koike et al. 2011). Such services aim to reduce DUP and tackle health and social inequalities in young people experiencing FEP (typically aged up to 35 years old), thus targeting improvement over a range of clinical, economic and social outcomes. We would expect (Kirkbride et al. 2006) such services to see at least $76 \%$ and $63 \%$ of all men and women, respectively, who would develop FEP in their lifetime (Kirkbride et al. 2006).

Proponents of EIS cite evidence to show that when intervention is sustained, people experiencing severe mental illness have improved clinical (Craig et al. 2004; Mihalopoulos et al. 2009) and social outcomes (Garety et al. 2006; Bertelsen et al. 2008; Mihalopoulos et al. 2009). Typically, however, EIS only provide support to young people in the first 3-5 years of disorder, before referring them on to standard care. Without continued intervention, some evidence indicates that initial gains may be eroded (Marshall \& Rathbone, 2011). This problem has been used by those on both sides of the EIS debate to justify the continued support or highlight the shortcomings of EIS-see Bosanac et al. (2010) and McGorry et al. (2010) for criticism and rebuttal of this and other aspects of EIS care. The provision of continued effective care for young people with psychosis after EIS is an important issue, discussed in greater detail elsewhere (Lester et al. 2012). There is a strong economic justification for EIS. Per participant annual costs are lower than through standard care (McCrone et al. 2011), particularly over time (Valmaggia et al. 2009). Also, there is evidence that every pound or dollar spent on EIS leads to exponential downstream cost savings; these are associated with fewer future inpatient admissions, lower future treatment costs for mental and physical health problems, and indirect savings associated with people remaining in or entering employment (Mihalopoulos et al. 2009; McCrone et al. 2011). Finally, EIS are seen as largely beneficial by the patients themselves and their carers (Lester et al. 2011, 2012).

The deployment of EIS has, however, attracted criticism on several grounds. These include lack of improvement in outcomes unless intervention is sustained (Marshall \& Rathbone, 2011), possible lack of clinical improvement in symptoms over standard care in the longer term (Bertelsen et al. 2008), issues surrounding the definition of caseness and DUP (Bosanac et al. 2010), ethical issues raised by treating those in the prodromal (pre-clinical) phase of psychosis [including possible stigmatization (Raven et al. 2012) and the administration of medication to non-clinical groups who may never have gone on to develop psychosis (Pelosi \& Birchwood, 2003; Raven et al. 2012)], discontinuities in care pathways (Pelosi, 2009) and possible age-sex discrimination (Pelosi \& Birchwood, 2003). Notwithstanding some evidence supporting the cost-effectiveness of EIS (Mihalopoulos et al. 2009; Valmaggia et al. 2009; McCrone et al. 2011), one particular criticism of such services is that resources could have been better invested in other areas of psychosis and psychiatric care (Pelosi \& Birchwood, 2003; Pelosi, 2009; Bosanac et al. 2010). Kelly et al. (2007), for example, have highlighted the need for flexible, adaptive EIS to fit in with existing local healthcare practices and culturally influenced help-seeking 


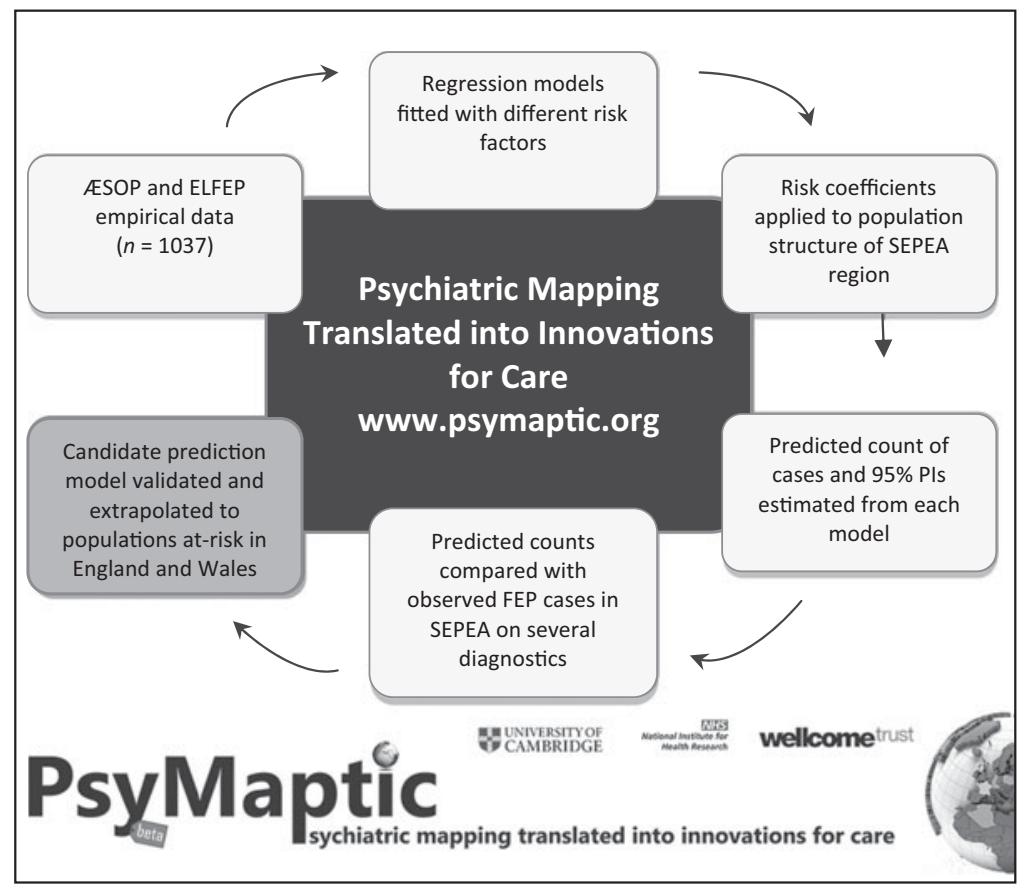

Fig. 1. Schematic overview of the PsyMaptic prediction process. AESOP, Aetiology and Ethnicity in Schizophrenia and Other Psychoses; ELFEP, East London First Episode Psychosis; SEPEA, Social Epidemiology of Psychoses in East Anglia; PI, prediction interval; FEP, first-episode psychosis.

behaviour in rural communities, where there may be insufficient demand for stand-alone EIS teams.

\section{Parity of esteem, EIS delivery and local need}

We, like Kelly et al. (2007), also note a more fundamental problem with EIS delivery: for such services to be efficient and effective they must be: (1) resourced according to anticipated local need; and (2) be designed to reflect the underlying sociocultural structure of the population at risk which they serve. We posit that mismatches between EIS delivery and utilization (see below) lie at the heart of continued controversies in regard to funding of EIS and other mental health services (Amos, 2012; Mihalopoulos et al. 2012). In countries where mental healthcare is predominantly provided by the state, addressing social and economic disparities in psychiatric morbidity and health service delivery has become an increasingly important political issue at a time of economic uncertainty (Department of Health, 2007, 2011; Council of Australian Governments, 2012). If EIS delivery can be based on more realistic models of predicted psychosis in different communities, centred on local need, then resources can be allocated more efficiently within the mental health system as a whole. The benefits of accurate prediction of local demand for EIS and other mental health services is not limited to potential gains in efficiency; explicitly modelling the underlying sociodemographic, economic and cultural determinants of mental health disorders should also reveal the probable structure of local demand, facilitating effective service delivery centred around the particular sociocultural needs of local populations. As such, a necessary precursor to achieving parity of esteem between physical and mental health will be creating the conditions for parity of esteem to arise within mental health, such that culturally sensitive resources are delivered efficiently and effectively based on local population needs across a range of mental health disorders. To do this, healthcare commissioners and policymakers need access to robust, precise predictions of anticipated service utilization, based on empirical data.

In this article, we showcase the development of one such tool, known as PsyMaptic (Psychiatric Mapping Translated into Innovations for Care; www. psymaptic.org) (see Fig. 1), which translates empirical population-based estimates of disease risk into expected morbidity in different populations, having taken into account variation in local population structures and exposure to socio-environmental characteristics associated with disorder. PsyMaptic is currently an incidence-based prediction tool for FEP in England and Wales, though the modelling methodology underpinning the tool (Kirkbride et al. 2013) can easily be extended to prevalence-based scenarios, other disorders or geographical regions where 
the epidemiology is well-characterized and accurate population denominator data are available. Here, we briefly set out the context under which the tool was developed, before providing an overview of the methodology, prediction validity and limitations of this approach.

\section{Background to EIS implementation in England}

EIS for people aged 14-35 years old in England were nationally commissioned by the Department of Health in 2002, based on a uniform incidence rate for service resourcing of around 51 new cases per 100000 people per year (Department of Health, 2001) ${ }^{1}+$. Although the accompanying Mental Health Policy Implementation Guide (MH-PIG) specified that '[a]n understanding of local epidemiology is needed as the size of the population covered will depend on a number of different factors including: Geography of the area; Health and Social service boundaries, [and] Demography and epidemiology' (Department of Health, 2001, p. 55), the Department of Health did not delineate how such variation should be integrated into service development. Since their inception anecdotal reports and service audits have emerged to suggest that under this uniform commissioning EIS capacity was either being outstripped by public utilization (Mahmmood \& Fisher, 2006), or that such services were operating under capacity (Tiffin \& Glover, 2007).

Although EIS funding is influenced by a range of local and national policy factors, and is not solely determined by anticipated caseloads, services in more deprived, urban populations were more likely to report running over capacity (Mahmmood \& Fisher, 2006; Lester et al. 2009). By contrast, while effective EIS delivery in rural areas faces a number of unique challenges (Craig, 2003; Kelly et al. 2007; Lester et al. 2009), rural services were generally more likely to see fewer than expected cases under the Department of Health's uniform rate (Tiffin \& Glover, 2007). In one audit, four of nine regional EIS leads suggested low caseloads 'were partly due to the original targets overestimating the case prevalence [sic] in non-urban areas' (Tiffin \& Glover, 2007). This mismatch threatens mental health service provision in different regions in different ways. In more urban areas, where the risk of psychotic disorder is elevated (Kirkbride et al. 2012a), services may not be able to meet targets to provide adequate care for services users. In less urban settings, where services may operate under capacity, future funding may be threatened if services do not meet national guidance which recommends that each

† The notes appear after the main text. key worker should manage a caseload of 15 service users.

\section{Development of the PsyMaptic prediction tool}

Fundamental to the development of our PsyMaptic prediction tool is the assertion that healthcare delivery should be evidence-based (McGorry, 2012). In developing PsyMaptic (Kirkbride et al. 2013) we investigated the validity of several different empirical models, informed by robust population-based FEP data from two large, methodologically similar epidemiological studies: the Aetiology and Ethnicity in Schizophrenia and Other Psychoses ( $Æ S O P)$ study and the East London First Episode Psychosis (ELFEP) study (Kirkbride et al. 2006, 2008). These studies were conducted prior to the introduction of EIS, and included 1037 people aged 16-64 years with FEP. This allowed us to precisely estimate the incidence rates of psychotic disorders in different sociodemographic groups in three areas of England (London, Nottinghamshire and Bristol). A total of six different negative binomial regression models were tested, which all included age group, sex, their interaction, and ethnic group as important predictors of psychosis risk. In addition, five of these models included a measure of the social environment, including four different components of deprivation or population density at the local authority district (LAD) level $(n=21)$. We retained regression coefficients from each model, and applied them to the population at risk in a new region, in order to predict the expected count of FEP cases according to the size of the population in different sociodemographic strata, given the model. These models were tested in the catchment area of a markedly different region, East Anglia, at a later period in time (between 2009 and 2012), where we had concurrently estimated observed FEP incidence, aged 16-35 years, as seen through six EIS in the Social Epidemiology of Psychoses in East Anglia (SEPEA) study (Kirkbride et al. 2012c). Only observed cases meeting International Classification of Diseases, tenth revision (ICD-10) clinical diagnosis for FEP 6 months after acceptance into the service were included in our comparison sample.

\section{Validation of PsyMaptic prediction models}

We validated each prediction model by comparing how closely it predicted observed caseloads in this new region according to a range of validation metrics (see Kirkbride et al. 2013). Our most accurate model for FEP prediction in EIS included age group, sex, their interaction, ethnic group and LAD-level population density. Overall this model predicted that 508 FEP cases, aged 16-35 years, would occur over a 
2.5-year period in East Anglia, with a 95\% prediction interval (95\% PI) of $459-559$ cases (Kirkbride et al. 2013). The observed number of FEP cases ascertained from the SEPEA study during this time period was 522. In addition, our model correctly ${ }^{2}$ predicted the number of cases observed in five out of six of our EIS and 19 out of 21 LADs. All our prediction models out-performed the Department of Health's uniform prediction rate, which over-predicted expected cases (716; 95\% PI 664-769) overall, and only predicted accurately in two out of six and thirteen out of twenty-one EIS and LAD, respectively. We applied our best-fitting model to the 2009 mid-year population estimates for all LADs in England and Wales to obtain national estimates of the predicted annual incidence of psychotic disorders, which we have translated into a free tool for public mental health (www.psymaptic.org). Overall our model predicts 5826 new FEP cases per year (95\% PI 5656-5990) in the age range 16-35 years in England, with just a further 92 cases in Wales (95\% PI 75-114). This is considerably fewer than the Department of Health's previous estimate $(n=7500)$ (Department of Health, 2000).

\section{Strengths and limitations of the PsyMaptic prediction tool}

Our models are predicated on clinically relevant caseloads meeting ICD-10 diagnostic criteria for psychotic disorder 6 months after EIS acceptance. They are not based on the broader range of psychopathology often seen at initial referral to EIS, a problem sometimes compounded by the important EIS policy not to diagnose at first presentation in order to allow symptom evolution, and avoid stigmatizing young people who may (or may not) be in their first episode of psychosis. Services will therefore require sufficient resourcing to manage the broader referral base that they are likely to see beyond the strict diagnosis of ICD-10 psychotic disorder. Reducing the false-positive rate in EIS presents a separate opportunity to improve pathways to care within the health system, and improve the delivery of services to young people who may require some degree of psychiatric triage and signposting to the most appropriate service.

The accurate translation of epidemiological models of disease risk into tools for public mental health planning and service commissioning should increase the efficiency and effectiveness of mental health provision in healthcare systems throughout the world. PsyMaptic provides proof of concept of one such approach. Unlike the current 'gold standard' for EIS commissioning in England, our approach dynamically adapts to anticipated local need for psychosis services in young people, and is responsive to changes in the sociodemographic structure of different communities over time. Because the PsyMaptic model translates robust coefficients of psychosis risk to the sociodemographic and socio-environmental profiles of the underlying population at risk in different regions, it highlights those communities where annual demand for services is likely to be highest (or lowest). This information should facilitate more efficient allocation of finite resources to EIS where they are most needed. One natural extension of PsyMaptic would clearly be to develop and apply similar models to other psychiatric disorders where the epidemiology is well characterized, including common mental disorders, dementia and autism spectrum disorders. Our prediction models could also be adapted to focus on the supply of cross-disorder mental health teams, including crisis and home resolution teams, intake and treatment teams and child and adolescent mental health services. Furthermore, because PsyMaptic predictions are based on local need, this tool could provide service planners with an indication of the likely sociodemographic composition of their services, paving the way for the effective delivery of culturally sensitive mental health care services.

We hope that our translational tool is a valuable resource for newly formed clinical commissioning groups, service planners, and EIS leads and teams in England and Wales. In the future, we hope to deploy the tool in other international settings. Our tool may also have utility for researchers planning studies in particular populations (i.e. specific age or ethnic groups). Our proposed approach, if reliable, will meet recent calls by the Department of Health and other institutions, including the Royal College of Psychiatrists, Royal College of General Practitioners and the Royal Society of Public Health, that health service provision should be based around local need (Joint Commissioning Panel for Mental Health, 2012).

\section{Conclusion}

Our approach highlights local need for psychosis services according to age, sex, ethnic group and level of urbanization. As such it begins to illuminate those communities that are likely to face the largest inequalities in regard to the burden of severe mental illness. A body of international research (van Os et al. 2000; Allardyce et al. 2005; Veling et al. 2008; Zammit et al. 2010), including our own work in England (Kirkbride et al. 2008, 2012a, b), now suggests that social inequalities themselves are associated with increased rates of psychotic illness. Tools to identify and tackle regional inequalities in the social and economic determinants of mental health and well-being, as well as in inequalities in the allocation of resources within and beyond 
the mental health system, can serve as the evidence base upon which to found effective service delivery for the prevention and management of mental health disorders. Developing these capabilities lies at the heart of many national political objectives to improve clinical, social and economic outcomes in people experiencing mental health problems, including in the USA (The White House, 2013) and UK (Department of Health, 2011). Parity of esteem between physical and mental health service provision will only begin to be achieved when we move towards parity of esteem within mental health systems. This will only be realized when service commissioning is underpinned by evidence-based tools that map psychiatric risk according to the local needs of different communities.

\section{Acknowledgements}

J.B.K. was supported by a Sir Henry Wellcome Research Fellowship from the Wellcome Trust (grant no. WT085540), through which the SEPEA study (www.sepea.org) was established. P.B.J. directs the National Institute for Health Research (NIHR) Collaboration for Leadership in Applied Health Research and Care (CLAHRC) for Cambridgeshire \& Peterborough and is supported by NIHR grant no. RP-PG-0606-1335. The SEPEA study has been adopted by the Mental Health Research Network (MHRN). The authors are grateful to the clinical services and staff participating in the SEPEA study, and the MHRN for their support.

\section{Declaration of Interest}

None.

\section{Notes}

1 The Department of Health recommended a uniform rate to commission EIS, which 'should manage 150 new cases per year... It is envisaged that each Early Intervention Service will cater for a population of around 1 million people.' [Department of Health (2001), p. 55]. At the time $29.4 \%$ of the English population were estimated to be aged 14-35 years old, suggesting that EIS in England were commissioned on the basis of a uniform rate of 51.0 FEP cases per 100000 person-years over the age range $14-35$ years (i.e. $[150 /(1000000 \times 0.294)] \times 100000)$.

2 We defined a 'correct' prediction to occur when the observed number of cases fell within the 95\% PIs for a given estimate. See Kirkbride et al. (2013) for full details of our methodology.

\section{References}

Addington J, Cadenhead KS, Cornblatt BA, Mathalon DH, McGlashan TH, Perkins DO, Seidman LJ, Tsuang MT, Walker EF, Woods SW, Addington JA, Cannon TD (2012). North American Prodrome Longitudinal Study (NAPLS 2): overview and recruitment. Schizophrenia Research 142, 77-82.

Allardyce J, Gilmour H, Atkinson J, Rapson T, Bishop J, McCreadie RG (2005). Social fragmentation, deprivation and urbanicity: relation to first-admission rates for psychoses. British Journal of Psychiatry 187, 401-406.

Amos A (2012). Assessing the cost of early intervention in psychosis: a systematic review. Australian and New Zealand Journal of Psychiatry 46, 719-734.

Bertelsen M, Jeppesen P, Petersen L, Thorup A, Ohlenschlaeger J, le Quach P, Christensen TO, Krarup G, Jorgensen P, Nordentoft M (2008). Five-year follow-up of a randomized multicenter trial of intensive early intervention vs standard treatment for patients with a first episode of psychotic illness: the OPUS Trial. Archives of General Psychiatry 65, 762-771.

Bosanac P, Patton GC, Castle DJ (2010). Early intervention in psychotic disorders: faith before facts? Psychological Medicine 40, 353-358.

Brietzke E, Araripe Neto AG, Dias A, Mansur RB, Bressan RA (2011). Early intervention in psychosis: a map of clinical and research initiatives in Latin America. Revista Brasileira de Psiquiatria 33 (Suppl. 2), s213-s224.

Brown S, Barraclough BM, Inskip H (2000). Causes of the excess mortality of schizophrenia. British Journal of Psychiatry 177, 212-217.

Brown S, Birtwistle J, Roe L, Thompson C (1999). The unhealthy lifestyle of people with schizophrenia. Psychological Medicine 29, 697-701.

Campion J, Bhui K, Bhugra D (2012). European Psychiatric Association (EPA) guidance on prevention of mental disorders. European Psychiatry 27, 68-80.

Caplan B, Zimmet SV, Meyer EC, Friedman-Yakoobian M, Monteleone T, Jude Leung Y, Guyer ME, Rood LL, Keshavan MS, Seidman LJ (2013). Prevention and recovery in early psychosis $\left(\right.$ PREP $\left.^{\circledR}\right)$ : building a public-academic partnership program in Massachusetts, United States. Asian Journal of Psychiatry 6, 171-177.

Council of Australian Governments (2012). The Roadmap for National Mental Health Reform 2012-2022. Australian Government: Canberra.

Craig T (2003). A step too soon or a step too far? Early intervention in psychosis. Journal of Mental Health 12, 335-339.

Craig TKJ, Garety P, Power P, Rahaman N, Colbert S, Fornells-Ambrojo M, Dunn G (2004). The Lambeth Early Onset (LEO) Team: randomised controlled trial of the effectiveness of specialised care for early psychosis. British Medical Journal 329, 1067.

Department of Health (2000). The NHS Plan: A Plan for Investment, a Plan for Reform. HMSO: London.

Department of Health (2001). Mental Health Policy Implementation Guide. National Health Service: London. 
Department of Health (2007). Guidance on Joint Strategic Needs Assessment. Department of Health: London.

Department of Health (2011). No Health Without Mental Health: A Cross-Government Mental Health Outcomes Strategy for People of All Ages. Department of Health: London.

Egede LE (2007). Major depression in individuals with chronic medical disorders: prevalence, correlates and association with health resource utilization, lost productivity and functional disability. General Hospital Psychiatry 29, 409-416.

Garety PA, Craig TK, Dunn G, Fornells-Ambrojo M, Colbert S, Rahaman N, Read J, Power P (2006). Specialised care for early psychosis: symptoms, social functioning and patient satisfaction: randomised controlled trial. British Journal of Psychiatry 188, 37-45.

Grant BF, Hasin DS, Chou SP, Stinson FS, Dawson DA (2004). Nicotine dependence and psychiatric disorders in the United States: results from the National Epidemiologic Survey on Alcohol and Related Conditions. Archives of General Psychiatry 61, 1107-1115.

Gustavsson A, Svensson M, Jacobi F, Allgulander C, Alonso J, Beghi E, Dodel R, Ekman M, Faravelli C, Fratiglioni L, Gannon B, Jones DH, Jennum P, Jordanova A, Jonsson L, Karampampa K, Knapp M, Kobelt G, Kurth T, Lieb R, Linde M, Ljungcrantz C, Maercker A, Melin B, Moscarelli M, Musayev A, Norwood F, Preisig M, Pugliatti M, Rehm J, Salvador-Carulla L, Schlehofer B, Simon R, Steinhausen HC, Stovner LJ, Vallat JM, Van den Bergh $P$, van Os J, Vos P, Xu W, Wittchen HU, Jonsson B, Olesen J (2011). Cost of disorders of the brain in Europe 2010. European Neuropsychopharmacology 21, 718-779.

Hui CL, Chang WC, Chan SK, Lee EH, Tam WW, Lai DC, Wong GH, Tang JY, Li FW, Leung KF, McGhee SM, Sham PC, Chen EY (2013). Early intervention and evaluation for adult-onset psychosis: the JCEP study rationale and design. Early Intervention in Psychiatry. Published online 28 February 2013. doi:10.1111/eip.12034.

Iyer SN, Mangala R, Thara R, Malla AK (2010). Preliminary findings from a study of first-episode psychosis in Montreal, Canada and Chennai, India: comparison of outcomes. Schizophrenia Research 121, 227-233.

James S, Das D (2012). Tobacco smoking in the Leicestershire Early Intervention in Psychosis Service: patient survey and service development. Early Intervention in Psychiatry 6, 110-110.

Joint Commissioning Panel for Mental Health (2012). Guidance for the Commissioning of Public Mental Health Services. Royal College of Psychiatry: London.

Kelly M, O'Meara Howard A, Smith J (2007). Early intervention in psychosis: a rural perspective. Journal of Psychiatric and Mental Health Nursing 14, 203-208.

Kirkbride JB, Barker D, Cowden F, Stamps R, Yang M, Jones PB, Coid JW (2008). Psychoses, ethnicity and socio-economic status. British Journal of Psychiatry 193, $18-24$.

Kirkbride JB, Errazuriz A, Croudace TJ, Morgan C, Jackson D, Boydell J, Murray RM, Jones PB (2012a). Incidence of schizophrenia and other psychoses in England,
1950-2009: a systematic review and meta-analyses. PLOS ONE 7, e31660.

Kirkbride JB, Fearon P, Morgan C, Dazzan P, Morgan K, Tarrant J, Lloyd T, Holloway J, Hutchinson G, Leff JP, Mallett RM, Harrison GL, Murray RM, Jones PB (2006). Heterogeneity in incidence rates of schizophrenia and other psychotic syndromes: findings from the 3-center ÆSOP Study. Archives of General Psychiatry 63, 250-258.

Kirkbride JB, Jackson D, Perez J, Fowler D, Winton F, Coid JW, Murray RM, Jones PB (2013). A population-level prediction tool for the incidence of first-episode psychosis: translational epidemiology based on cross-sectional data. BMJ Open 3, e001998.

Kirkbride JB, Jones PB, Ullrich S, Coid JW (2012b). Social deprivation, inequality, and the neighborhood-level incidence of psychotic syndromes in East London. Schizophrenia Bulletin. Published online 12 December 2012. doi:10.1093/schbul/sbs151.

Kirkbride JB, Stubbins C, Jones PB (2012c). Psychosis incidence through the prism of early intervention services. British Journal of Psychiatry 200, 156-157.

Kohn R, Saxena S, Levav I, Saraceno B (2004). The treatment gap in mental health care. Bulletin of the World Health Organization 82, 858-866.

Koike S, Nishida A, Yamasaki S, Ichihashi K, Maegawa S, Natsubori T, Harima H, Kasai K, Fujita I, Harada M, Okazaki Y (2011). Comprehensive early intervention for patients with first-episode psychosis in Japan (J-CAP): study protocol for a randomised controlled trial. Trials 12, 156.

Lasser K, Boyd JW, Woolhandler S, Himmelstein DU, McCormick D, Bor DH (2000). Smoking and mental illness: a population-based prevalence study. Journal of the American Medical Association 284, 2606-2610.

Laursen TM, Munk-Olsen T, Vestergaard M (2012). Life expectancy and cardiovascular mortality in persons with schizophrenia. Current Opinion in Psychiatry 25, 83-88.

Lawrence D, Kisely S, Pais J (2010). The epidemiology of excess mortality in people with mental illness. Canadian Journal of Psychiatry 55, 752-760.

Lee MS, Ahn SR, Park JI, Chung YC (2012). Development of an early psychosis intervention system in Korea: focus on the continuing care system for first-episode psychosis treatment in Seoul. East Asian Archives of Psychiatry 22, 105-109.

Lester H, Birchwood M, Bryan S, England E, Rogers H, Sirvastava N (2009). Development and implementation of early intervention services for young people with psychosis: case study. British Journal of Psychiatry 194, 446-450.

Lester H, Khan N, Jones P, Marshall M, Fowler D, Amos T, Birchwood M (2012). Service users' views of moving on from early intervention services for psychosis: a longitudinal qualitative study in primary care. British Journal of General Practice 62, e183-e190.

Lester H, Marshall M, Jones P, Fowler D, Amos T, Khan N, Birchwood M (2011). Views of young people in early intervention services for first-episode psychosis in England. Psychiatric Services 62, 882-887. 
Lord O, Malone D, Mitchell AJ (2010). Receipt of preventive medical care and medical screening for patients with mental illness: a comparative analysis. General Hospital Psychiatry 32, 519-543.

Mahmmood MA, Fisher H (2006). The incidence of first episode psychosis in inner London: findings from the Lambeth Early Onset (LEO) service. Schizophrenia Research 86, 0548.

Mangalore R, Knapp M (2007). Cost of schizophrenia in England. Journal of Mental Health Policy and Economics 10, 23-41.

Marshall M, Lewis S, Lockwood A, Drake R, Jones P, Croudace $T$ (2005). Association between duration of untreated psychosis and outcome in cohorts of first-episode patients: a systematic review. Archives of General Psychiatry 62, 975-983.

Marshall M, Rathbone J (2011). Early intervention for psychosis. Schizophrenia Bulletin 37, 1111-1114.

McCreadie RG (2003). Diet, smoking and cardiovascular risk in people with schizophrenia. British Journal of Psychiatry 183, 534-539.

McCrone P, Park A-L, Knapp M (2011). Early intervention for psychosis. In Mental Health Promotion and Mental Illness Prevention (ed. M. Knapp, D. McDaid and M. Parsonage), pp. 16-17. Department of Health: London.

McGorry P (2012). At issue: Cochrane, early intervention, and mental health reform: analysis, paralysis, or evidence-informed progress? Schizophrenia Bulletin 38, 221-224.

McGorry P, Johanessen JO, Lewis S, Birchwood M, Malla A, Nordentoft M, Addington J, Yung A (2010). Early intervention in psychosis: keeping faith with evidence-based health care. Psychological Medicine 40, 399-404.

McGorry PD, Edwards J, Mihalopoulos C, Harrigan SM, Jackson HJ (1996). EPPIC: an evolving system of early detection and optimal management. Schizophrenia Bulletin 22, 305-326.

McManus S, Meltzer H, Campion J (2010). Cigarette Smoking and Mental Health in England: Data from the Adult Psychiatric Morbidity Survey 2007. National Centre for Social Research: London.

Mihalopoulos C, Harris M, Henry L, Harrigan S, McGorry P (2009). Is early intervention in psychosis cost-effective over the long term? Schizophrenia Bulletin 35, 909-918.

Mihalopoulos C, McCrone P, Knapp M, Johannessen JO, Malla A, McGorry P (2012). The costs of early intervention in psychosis: restoring the balance. Australian and New Zealand Journal of Psychiatry 46, 808-811.

Mitchell AJ, Malone D, Doebbeling CC (2009). Quality of medical care for people with and without co-morbid mental illness and substance misuse: systematic review of comparative studies. British Journal of Psychiatry 194, 491-499.

Mortensen PB, Juel K (1993). Mortality and causes of death in first admitted schizophrenic patients. British Journal of Psychiatry 163, 183-189.
Moussavi S, Chatterji S, Verdes E, Tandon A, Patel V, Ustun B (2007). Depression, chronic diseases, and decrements in health: results from the World Health Surveys. Lancet 370, 851-858.

Pelosi A (2009). Is early intervention in the major psychiatric disorders justified? No. British Medical Journal 337, a710.

Pelosi AJ, Birchwood M (2003). Is early intervention for psychosis a waste of valuable resources? British Journal of Psychiatry 182, 196-198.

Perkins DO, Gu H, Boteva K, Lieberman JA (2005). Relationship between duration of untreated psychosis and outcome in first-episode schizophrenia: a critical review and meta-analysis. American Journal of Psychiatry 162, 1785-1804.

Raven M, Stuart GW, Jureidini J (2012). 'Prodromal' diagnosis of psychosis: ethical problems in research and clinical practice. Australian and New Zealand Journal of Psychiatry 46, 64-65.

Rossler W, Salize HJ, van Os J, Riecher-Rossler A (2005). Size of burden of schizophrenia and psychotic disorders. European Neuropsychopharmacology 15, 399-409.

Royal College of Psychiatrists (2012). Joint Call for Parity of Esteem on World Mental Health Day. Royal College of Psychiatrists: London.

Royal College of Psychiatrists (2013). Whole-Person Care: From Rhetoric to Reality. Royal College of Psychiatrists: London.

Saha S, Chant D, McGrath J (2007). A systematic review of mortality in schizophrenia: is the differential mortality gap worsening over time? Archives of General Psychiatry 64, 1123-1131.

The White House (2013). Background on the National Conference on Mental Health. Office of the Press Secretary: Washington, DC.

Tiffin PA, Glover G (2007). From commitment to reality: early intervention in psychosis services in England. Early Intervention in Psychiatry 1, 104-107.

Valmaggia LR, McCrone P, Knapp M, Woolley JB, Broome MR, Tabraham P, Johns LC, Prescott C, Bramon E, Lappin J, Power P, McGuire PK (2009). Economic impact of early intervention in people at high risk of psychosis. Psychological Medicine 39, 1617-1626.

van Os J, Driessen G, Gunther N, Delespaul P (2000). Neighbourhood variation in incidence of schizophrenia. Evidence for person-environment interaction. British Journal of Psychiatry 176, 243-248.

Veling W, Susser E, van Os J, Mackenbach JP, Selten J-P, Hoek HW (2008). Ethnic density of neighborhoods and incidence of psychotic disorders among immigrants. American Journal of Psychiatry 165, 66-73.

Wade D, Harrigan S, Edwards J, Burgess PM, Whelan G, McGorry PD (2006). Course of substance misuse and daily tobacco use in first-episode psychosis. Schizophrenia Research 81, 145-150.

Zammit S, Lewis G, Rasbash J, Dalman C, Gustafsson J-E, Allebeck P (2010). Individuals schools, and neighborhood: a multilevel longitudinal study of variation in incidence of psychotic disorders. Archives of General Psychiatry 67, 914-922. 